Special Issue of the 8th International Advances in Applied Physics and Materials Science Congress (APMAS 2018)

\title{
Two-Dimensional Mixed-Metal Complexes Composed of Mixed-Valent Dinuclear Ruthenium(II,III) Carboxylate and Tetracyanidopalladate(II) Units
}

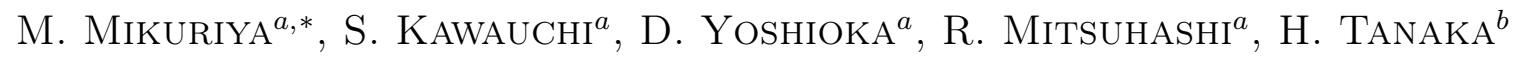 \\ AND M. HANDA ${ }^{b}$ \\ ${ }^{a}$ Kwansei Gakuin University, School of Science and Technology, 2-1 Gakuen, Sanda 669-1337, Japan \\ ${ }^{b}$ Shimane University, Interdisciplinary Graduate School of Science and Engineering, 1060 Nishikawatsu, \\ Matsue 669-8504, Japan
}

\begin{abstract}
Two-dimensional mixed-metal complexes composed of ruthenium(II,III) carboxylate $\left(\mathrm{Ru}_{2}(\mathrm{RCOO})_{4}^{+}\right)$and tetracyanidopalladate(II) $\left(\mathrm{Pd}(\mathrm{CN})_{4}^{2-}\right)$ units, $\left[\left\{\mathrm{Ru}_{2}(\mathrm{RCOO})_{4}\right\}_{2} \mathrm{Pd}(\mathrm{CN})_{4}\right]\left(\mathrm{R}=\mathrm{CH}_{3}(1), \mathrm{C}_{2} \mathrm{H}_{5}(2), t-\mathrm{C}_{4} \mathrm{H}_{9}\right.$ (3)), were synthesized and characterized by elemental analysis, infrared and UV-vis-NIR spectra. Temperaturedependence of magnetic susceptibility $(2-300 \mathrm{~K})$ of $(2)$ showed that a weak antiferromagnetic interaction through the $\mathrm{Pd}(\mathrm{CN})_{4}^{2-}$ unit between the $\mathrm{Ru}_{2}\left(\mathrm{C}_{2} \mathrm{H}_{5} \mathrm{COO}\right)_{4}^{+}$units with $z J$ (the exchange integral multiplied by the number of interacting neighbors) $=-0.1 \mathrm{~cm}^{-1}$ and $D$ (zero-field splitting parameter) $=75 \mathrm{~cm}^{-1}$. The $\mathrm{N}_{2}$-adsorption

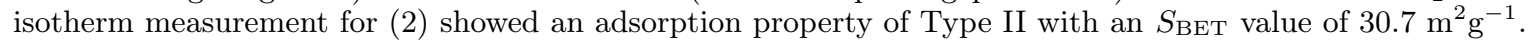

DOI: 10.12693/APhysPolA.135.837

PACS/topics: magnetic property, antiferromagnetic interaction, dinuclear ruthenium carboxylate, cyanidometalate, adsorption property

\section{Introduction}

Dinuclear metal carboxylates with a lantern-like or paddle-wheel-like dinuclear core have attracted much attention because of their unique dinuclear core and potential application such as molecule-based magnetic materials, porous materials, and mesogenic materials [1-4]. Among these compounds, mixed-valent dinuclear ruthenium(II,III) carboxylates, $\left[\mathrm{Ru}_{2}(\mathrm{RCOO})_{4}\right]^{+}$, are unique metal-metal bonded systems and can be used as a spinsource within the metal-metal bond for construction of magnetic materials [3-17]. In order to construct magnetic materials, linking ligand is an important factor determining dimensionality of metal-assembled systems. In this context, cyanidometalate complexes are useful linking ligands and some of them are directed for dinuclear ruthenum carboxylates [18-29]. We found ferrimagnetic behaviors in mixed-metal systems with hexacyanidoferrate(III) $\mathrm{Fe}(\mathrm{CN})_{6}^{3-}[18]$ and octacyanidotungstate(V) $\mathrm{W}(\mathrm{CN})_{8}^{3-}[23,24]$. On the other hand, weak antiferromagnetic interaction was observed in mixed-metal complexes with dicyanidoargentate $(\mathrm{I}) \mathrm{Ag}(\mathrm{CN})_{2}^{-}$[25], tetracyanidonickelate(II) $\mathrm{Ni}(\mathrm{CN})_{4}^{2-}[26,29]$, tetracyanidoplatinate(II) $\operatorname{Pt}(\mathrm{CN})_{4}^{2-}[27,28]$, and hexacyanidocobaltate(III) $\mathrm{Co}(\mathrm{CN})_{6}^{3-}$ [18]. It should be noticeable that the mixed-metal complex with tetracyanidoplatinate(II), $\left[\left\{\mathrm{Ru}_{2}\left(\mathrm{CH}_{3} \mathrm{COO}\right)_{4}\right\}_{2} \mathrm{Pt}(\mathrm{CN})_{4}\right]$, has a two-dimensional structure by assembling of dinuclear ruthenium(II,III)

*corresponding author; e-mail: junpei@kwansei.ac.jp and tetracyanidoplatinate(II) units, forming a porous structure with adsorbing property for nitrogen gas [28]. This encouraged us to study mixed metal complexes of ruthenium(II,III) carboxylates with tetracyanidopalladate(II) as shown in Fig. 1, because such system will give a similar two-dimensional structure. In this study, we will report on this system.

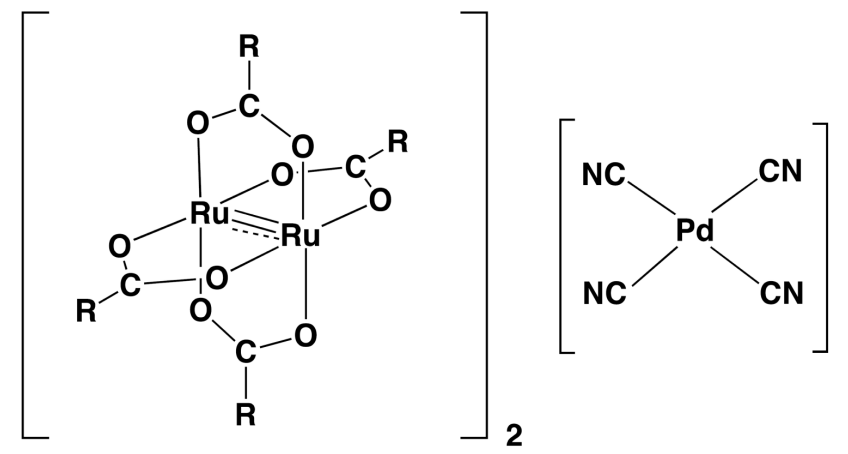

Fig. 1. Chemical structure of the mixed-metal system of $\left[\mathrm{Ru}_{2}(\mathrm{RCOO})_{4}\right]^{+}$and $\left[\mathrm{Pd}(\mathrm{CN})_{4}\right]^{2-}$.

\section{Experimental procedure}

\subsection{Materials}

Tetrafluoroborate of dinuclear ruthenium(II,III) carboxylates were prepared by a method described in the literature $[11,17]$. All of other reagents were commercially available and used as received. 


\subsection{Synthesis of $\left[\left\{\mathrm{Ru}_{2}(\mathrm{RCOO})_{4}\right\}_{2} \mathrm{Pd}(\mathrm{CN})_{4}\right]_{n}$}

$\left[\left\{\mathrm{Ru}_{2}\left(\mathrm{CH}_{3} \mathrm{COO}\right)_{4}\right\}_{2} \mathrm{Pd}(\mathrm{CN})_{4}\right]_{n}$ (1): To an aqueous solution $(5 \mathrm{~mL})$ of $\mathrm{K}_{2}\left[\mathrm{Pd}(\mathrm{CN})_{4}\right] \cdot 3 \mathrm{H}_{2} \mathrm{O}(24.0 \mathrm{mg}$, $0.0607 \mathrm{mmol})$, an aqueous solution $(5 \mathrm{~mL})$ of $\left[\mathrm{Ru}_{2}\left(\mathrm{CH}_{3} \mathrm{COO}\right)_{4}\left(\mathrm{H}_{2} \mathrm{O}\right)_{2}\right] \mathrm{BF}_{4}(108.3 \mathrm{mg}, 0.193 \mathrm{mmol})$ was added. The reaction mixture was stirred overnight, the resulting yellowish-brown precipitate was filtered off, washed with water and dried in vacuo. Yield, $100.5 \mathrm{mg}$ (93\%). Anal. Found: C, 22.39; H, 2.57; N, 4.87\%. Calc. for $\mathrm{C}_{20} \mathrm{H}_{24} \mathrm{~N}_{4} \mathrm{O}_{16} \mathrm{PdRu}_{4}$ : C, 22.10; H, 2.23; N, 5.15\%. IR $\left(\mathrm{KBr}, \mathrm{cm}^{-1}\right): 2142(\nu \mathrm{CN}), 1462\left(\nu_{a s} \mathrm{COO}\right), 1421$ $\left(\nu_{s} \mathrm{COO}\right)$. Diffused reflectance spectra: $\lambda_{\max } 250,445$, and 1052 (br) nm.

$\left[\left\{\mathrm{Ru}_{2}\left(\mathrm{C}_{2} \mathrm{H}_{5} \mathrm{COO}\right)_{4}\right\}_{2} \mathrm{Pd}(\mathrm{CN})_{4}\right]_{n}$ (2): This compound was obtained as brown precipitate by the reaction of $\left[\mathrm{Ru}_{2}\left(\mathrm{C}_{2} \mathrm{H}_{5} \mathrm{COO}\right)_{4}\left(\mathrm{H}_{2} \mathrm{O}\right)_{2}\right] \mathrm{BF}_{4}(104.3 \mathrm{mg}: 0.169 \mathrm{mmol})$ and $\mathrm{K}_{2}\left[\mathrm{Pd}(\mathrm{CN})_{4}\right] \cdot 3 \mathrm{H}_{2} \mathrm{O}(24.6 \mathrm{mg}, 0.0852 \mathrm{mmol})$ using the same method as that of 1 . Yield, $74.8 \mathrm{mg}(72 \%)$. Anal. Found: C, 27.76; H, 2.95; N, 4.94\%. Calc. for $\mathrm{C}_{28} \mathrm{H}_{40} \mathrm{~N}_{4} \mathrm{O}_{16} \mathrm{PdRu}_{4}$ : C, 28.04; $\mathrm{H}, 3.36 ; \mathrm{N}, 4.67 \%$. IR $\left(\mathrm{KBr}, \mathrm{cm}^{-1}\right): 2148(\nu \mathrm{CN}), 1447\left(\nu_{a s} \mathrm{COO}\right), 1426$ $\left(\nu_{s} \mathrm{COO}\right)$. Diffused reflectance spectra: $\lambda_{\max } 258,445$, and $1047(\mathrm{br}) \mathrm{nm}$.

$\left[\left\{\mathrm{Ru}_{2}\left(t-\mathrm{C}_{4} \mathrm{H}_{9} \mathrm{COO}\right)_{4}\right\}_{2} \mathrm{Pd}(\mathrm{CN})_{4}\right]_{\mathrm{n}} \quad(3)$ : This compound was obtained as brown precipitate by the reaction of $\left[\mathrm{Ru}_{2}\left(t-\mathrm{C}_{4} \mathrm{H}_{9} \mathrm{COO}\right)_{4}\left(\mathrm{H}_{2} \mathrm{O}\right)_{2}\right]_{\mathrm{BF}_{4}}(106.8 \mathrm{mg}$, $0.1464 \mathrm{mmol})$ and $\mathrm{K}_{2}\left[\mathrm{Pd}(\mathrm{CN})_{4}\right] \cdot 3 \mathrm{H}_{2} \mathrm{O}(25.6 \mathrm{mg}$, $0.0887 \mathrm{mmol}$ ) using the same method as that of 1 . Yield, $60.9 \mathrm{mg}(49 \%)$. Anal. Found: C, 37.26; H, 5.51; N, 3.71\%. Calc. for $\mathrm{C}_{44} \mathrm{H}_{72} \mathrm{~N}_{4} \mathrm{O}_{16} \mathrm{PdRu}_{4}$ : C, 37.12; H, 5.10; $\mathrm{N}, 3.94 \%$. IR ( $\left.\mathrm{KBr}, \mathrm{cm}^{-1}\right): 2142(\nu \mathrm{CN}), 1449\left(\nu_{a s} \mathrm{COO}\right)$, $1421\left(\nu_{s} \mathrm{COO}\right)$. Diffused reflectance spectra: $\lambda_{\max } 254$, 446, and 1060 (br) nm.

\subsection{Characterization}

Elemental analyses were performed on a Thermo Finnigan FLASH EA1112 analyzer. Infrared spectra were recorded on a JASCO MFT-2000 spectrometer as a KBr pellet. Solid-state UV-Vis-NIR spectra were recorded in the range of $200-1500 \mathrm{~nm}$ on a Shimadzu UV-3100 spectrophotometer (reflection method). Temperature dependence of magnetic susceptibility was measured using a Quantum Design MPMS XL SQUID magnetometer. The data were corrected for diamagnetism of the constituent atoms using the Pascal constants [30]. Adsorption measurements for $\mathrm{N}_{2}$ were performed by a MicrotracBEL BELSORP-mini II. Prior to the adsorption, the sample was evacuated at $298 \mathrm{~K}$ for $2 \mathrm{~h}$.

\section{Results and discussion}

Elemental analysis data of the isolated complexes are in accordance with the $2: 1\left(\mathrm{Ru}_{2}(\mathrm{RCOO})_{4}: \operatorname{Pd}(\mathrm{CN})_{4}\right)$ formulation $\left[\left\{\mathrm{Ru}_{2}(\mathrm{RCOO})_{4}\right\}_{2} \mathrm{Pd}(\mathrm{CN})_{4}\right]\left(\mathrm{R}=\mathrm{CH}_{3}(1)\right.$, $\mathrm{C}_{2} \mathrm{H}_{5}$ (2), and $\left.t-\mathrm{C}_{4} \mathrm{H}_{9}(3)\right)$. As shown in Fig. 2, IR data showed a strong $\nu(\mathrm{CN})$ stretching band of $\mathrm{Pd}(\mathrm{CN})_{4}^{2-}$ moiety at $2142-2148 \mathrm{~cm}^{-1}$ and this band appeared with a higher energy shift compared with that of $\mathrm{K}_{2} \mathrm{Pd}(\mathrm{CN})_{4} \cdot 3 \mathrm{H}_{2} \mathrm{O}\left(2128 \mathrm{~cm}^{-1}\right)$ similarly to the $\left[\left\{\mathrm{Ru}_{2}\left(\mathrm{CH}_{3} \mathrm{COO}\right)_{4}\right\}_{2} \mathrm{Pt}(\mathrm{CN})_{4}\right]$ complex which has a twodimensional polymer structure [28], suggesting the coordination of the $\mathrm{CN}$ groups to the dinuclear ruthenium units to form a two-dimensional sheet. The $\nu_{a s}(\mathrm{COO})$ and $\nu_{s}(\mathrm{COO})$ stretching bands appeared at $1447-1462$ and $1421-1426 \mathrm{~cm}^{-1}$, respectively, with the energy difference characteristic of syn-syn bridging carboxylate $[12,15,31]$, suggesting the dinuclear unit is preserved upon the coordination of the tetracyanidopalladate(II) unit to form a two-dimensional sheet like the $\left[\left\{\mathrm{Ru}_{2}\left(\mathrm{CH}_{3} \mathrm{COO}\right)_{4}\right\}_{2} \mathrm{Pt}(\mathrm{CN})_{4}\right]$ complex [28]. The twodimensional sheet structure was confirmed by the X-ray crystallography for the $\left[\left\{\mathrm{Ru}_{2}\left(\mathrm{C}_{2} \mathrm{H}_{5} \mathrm{COO}\right)_{4}\right\}_{2} \mathrm{Pd}(\mathrm{CN})_{4}\right]$ complex [32].

As shown in Fig. 3, the diffuse reflectance spectra of 1,2 , and 3 showed a broad band at $1047-1060 \mathrm{~nm}$ in the near-infrared region. The band can be assigned to the $\delta\left(\mathrm{Ru}_{2}\right) \rightarrow \delta^{*}\left(\mathrm{Ru}_{2}\right)$ transition band and showed a red shift compared with that of $\left[\mathrm{Ru}_{2}(\mathrm{RCOO})_{4}\left(\mathrm{H}_{2} \mathrm{O}\right)_{2}\right] \mathrm{BF}_{4}$ $(\sim 990 \mathrm{~nm})$, suggesting the axial coordination of the cyanido group of $\operatorname{Pd}(\mathrm{CN})_{4}^{2-}$ unit $[3,5,25]$. The spectra also contain a distinctive band at around $445 \mathrm{~nm}$, which can be assigned as $\pi\left(\mathrm{Ru}-\mathrm{O}, \mathrm{Ru}_{2}\right) \rightarrow \pi^{*}\left(\mathrm{Ru}_{2}\right)$ transition $[3,5,25]$.

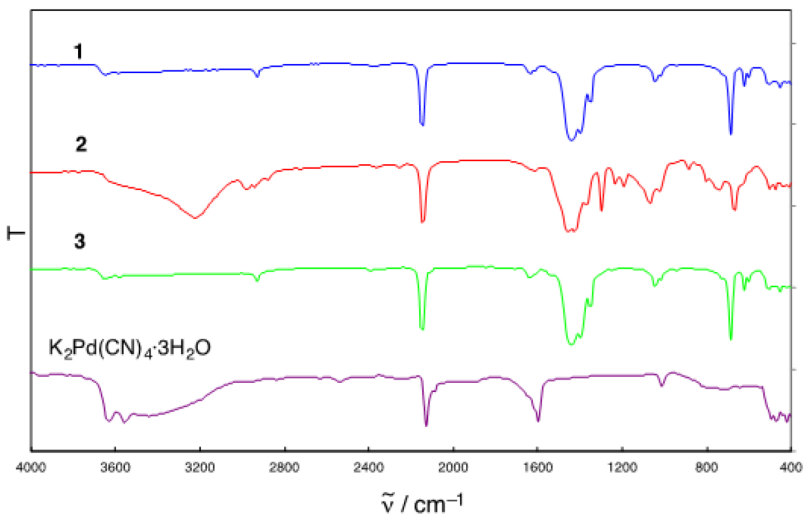

Fig. 2. Infrared spectra of (1), (2), (3), and $\mathrm{K}_{2} \mathrm{Pd}(\mathrm{CN})_{4} \cdot 3 \mathrm{H}_{2} \mathrm{O}$.

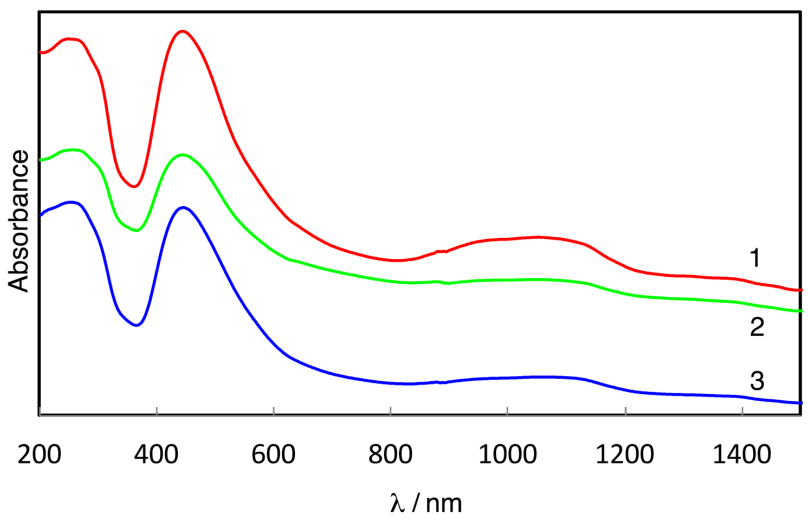

Fig. 3. Diffused reflectance spectra of (1), (2), and (3). 
Magnetic susceptibility measurement was made for (2) in the temperature range of $2-300 \mathrm{~K}$. The magnetic data of (2) are shown in Fig. 4 in the form of $\mu_{\mathrm{M}}$ plot, where $\mu_{\mathrm{M}}$ is the molar magnetic moment per $\left\{\mathrm{Ru}_{2}(\mathrm{RCOO})_{4}\right\}\left\{\mathrm{Pd}(\mathrm{CN})_{4}\right\}_{1 / 2}$ unit. The magnetic moment $\mu_{\mathrm{M}}$ at $300 \mathrm{~K}$ is $4.48 \mu_{\mathrm{B}}$, a little higher than the effective magnetic moment of $3.87 \mu_{\mathrm{B}}$, which is expected for a magnetically isolated dinuclear $\mathrm{Ru}_{2}^{\mathrm{II}}$, III $S=3 / 2$ ion and one half of $\operatorname{Pd}^{\mathrm{II}} S=0$ ion. Like the other dinuclear $\mathrm{Ru}_{2}^{\text {II, III }}$ polymer complexes with diamagnetic cyanidometallate $(S=0)$ [18, 25-29], the magnetic moment is decreased with lowering the temperature due to the zero-field splitting $(D)$, followed by further decrease in the magnetic moment closing to $2 \mathrm{~K}$ due to the antiferromagnetic interaction through the tetracyanidopalladate(II) ligand. The magnetic behaviors can be explained by using the equations (1)-(4) for the $S=3 / 2$ system with a zero-field splitting of $\mathrm{Ru}_{2}^{\mathrm{II}, \mathrm{III}}$ core, the inter-dinuclear-units interaction being taken into account by the mean-field approximation [5]:

$$
\chi^{\prime}=\frac{\chi}{1-\frac{2 z J \chi}{N g^{2} \mu_{\mathrm{B}}^{2}}}
$$

where $z J$ is the exchange energy multiplied by the number $(z)$ of interacting neighbors, and $\chi$ is the magnetic susceptibility,

$$
\chi=\frac{\chi_{\|}+2 \chi_{\perp}}{3}
$$

where $\chi_{\|}$and $\chi_{\perp}$ are magnetic susceptibility terms defined as follows:

$$
\begin{aligned}
\chi_{\|} & =\frac{N g^{2} \mu_{\mathrm{B}}^{2}}{k T} \frac{1+9 \exp \left(\frac{2 D}{k T}\right)}{4}\left[1+\exp \left(-\frac{2 D}{k T}\right)\right] \\
\chi_{\perp} & =\frac{N g^{2} \mu_{\mathrm{B}}^{2}}{k T} \frac{4+\frac{3 k T}{D}\left(1-\exp \left(-\frac{2 D}{k T}\right)\right)}{4} \\
& \times\left(1+\exp \left(-\frac{2 D}{k T}\right)\right)
\end{aligned}
$$

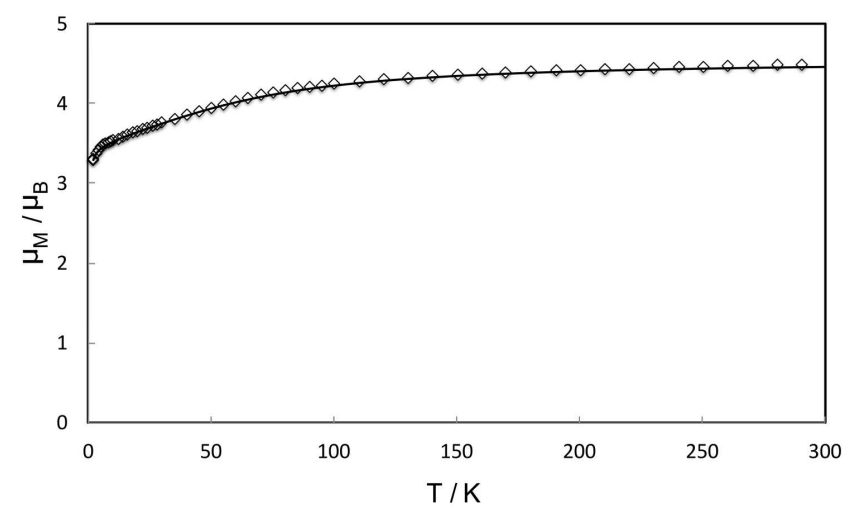

Fig. 4. Temperature dependence of magnetic moment of (2). The solid line was drawn by the calculated values with the parameters described in the text.
The best-fitting process gave the parameters with $g=$ $2.3, D=75 \mathrm{~cm}^{-1}, z J=-0.1 \mathrm{~cm}^{-1}$ for (2), confirming a weak antiferromagnetic interaction through the tetracyanidopalladate(II) group between the $3 / 2$ spins of dinuclear ruthenium(II,III) cores.

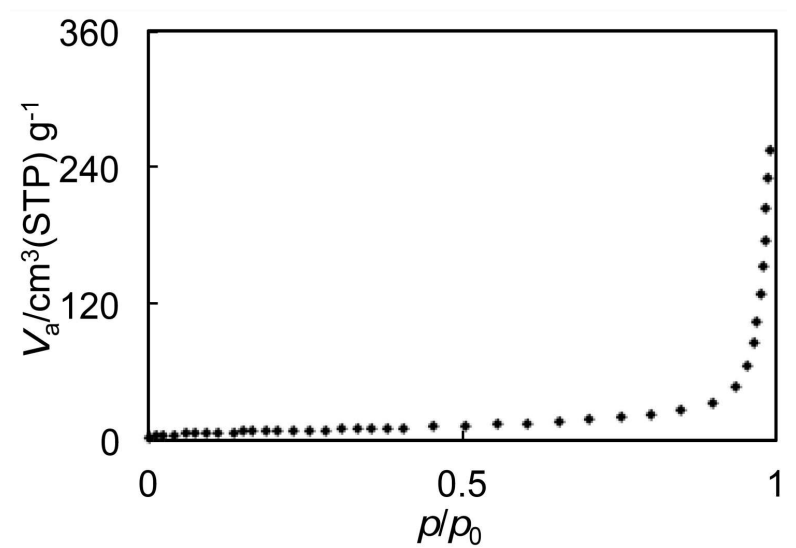

Fig. 5. The adsorption isotherm of $\mathrm{N}_{2}$ at $77 \mathrm{~K}$ for (2).

We measured the adsorption property of (2) for $\mathrm{N}_{2}$ to see the possibility of any porous structure. The adsorption isotherm of $\mathrm{N}_{2}$ at $77 \mathrm{~K}$ showed that the complex has an adsorption property with Type II behavior having an $S_{\mathrm{BET}}$ value of $30.7 \mathrm{~m}^{2} \mathrm{~g}^{-1}$, meaning that no micropore exists in (2) (Fig. 5). The present result suggests that a two-dimensional sheet may be constituted with a smaller size of void in (2). This is in accordance with the crystal structure of (2) [32].

\section{Conclusion}

New mixed-metal complexes with the formulation of $\left[\left\{\mathrm{Ru}_{2}(\mathrm{RCOO})_{4}\right\}_{2} \mathrm{Pd}(\mathrm{CN})_{4}\right] \quad\left(\mathrm{R}=\mathrm{CH}_{3}(1), \mathrm{C}_{2} \mathrm{H}_{5}\right.$ (2), and $\left.t-\mathrm{C}_{4} \mathrm{H}_{9}(3)\right)$ were synthesized by introducing tetracyanidopalladate(II) ion for ruthenium(II,III) acetate, propionate, and pivalate. The elemental analysis, IR, and UV-vis-NIR spectra supported the alternating arrangement of the $\mathrm{Ru}_{2}(\mathrm{RCOO})_{4}$ and $\mathrm{Pd}(\mathrm{CN})_{4}$ units to form a two-dimensional sheet. The propionate complex showed a weak antiferromagnetic interaction between the $3 / 2$ spins of the $\mathrm{Ru}_{2}\left(\mathrm{C}_{2} \mathrm{H}_{5} \mathrm{COO}\right)_{4}$ units through the tetracyanidopalladate(II) ligand within the two-dimensional sheet. The $\mathrm{N}_{2}$-adsorption measurement suggested a smaller size of void in the two-dimensional sheet compared with that of the $\mathrm{Ru}_{2}-\mathrm{Pt}$ complex [28]. The obtained results here are important to consider porous magnetic materials of mixed-metal systems.

\section{Acknowledgments}

The present work was partially supported by Grantin-Aid for Scientific Research Nos. 16K05722 and 17K05820 from the Ministry of Education, Culture, 
Sports, Science and Technology (MEXT, Japan). The magnetic measurements were performed at the Institute for Molecular Science, supported by Nanotechnology Platform (Molecule and Material Sythesis) of the MEXT, Japan.

\section{References}

[1] F.A. Cotton, C.A. Murillo, R.A. Walton, Multiple Bonds between Metal Atoms, 3rd ed., Springer Science and Business Media, New York 2005.

[2] M. Mikuriya, Bull. Jpn. Soc. Coord. Chem 52, 17 (2008).

[3] M.A.S. Aquino, Coord. Chem. Rev 248, 1025 (2004).

[4] M.A.S. Aquino, Coord. Chem. Rev. 170, 141 (1998).

[5] M. Mikuriya, D. Yoshioka, M. Handa, Coord. Chem. Rev 250, 2194 (2006).

[6] Y. Sayama, M. Handa, M. Mikuriya, R. Nukada, I. Hiromitsu, K. Kasuga, in: Coordination Chemistry at the Turn of the Century, Eds. G. Ondrejovic, A. Sirota, Slovak Technical University Press, Bratislava 1999, p. 447.

[7] H. Ishida, M. Handa, M. Mikuriya, X-ray Struct. Anal. Online 30, 9 (2014).

[8] Y. Hiraoka, T. Ikeue, H. Sakiyama, F. Guegan, D. Luneau, B. Gillon, I. Hiromitsu, D. Yoshioka, M. Mikuriya, Y. Kataoka, M. Handa, Dalton Trans. 44, 13439 (2015).

[9] H. Ishida, M. Handa, I. Hiromitsu, M. Mikuriya, Chem. J. Moldova 4, 90 (2009).

[10] H.Ishida, M. Handa, T. Ikeue, J. Taguchi, M. Mikuriya, Chem. Papers 64, 767 (2010).

[11] Y. Sayama, M. Handa, M. Mikuriya, I. Hiromitsu, K. Kasuga, Bull. Chem. Soc. Jpn 73, 2499 (2000).

[12] D. Yoshioka, M. Mikuriya, M. Handa, Bull Chem. Soc. Jpn. 77, 2205 (2004).

[13] H. Ishida, M. Handa, I. Hiromitsu, M. Mikuriya, Chem. Papers 67, 743 (2013).

[14] M. Handa, H. Ishida, K. Ito, T. Adachi, T. Ikeue, I. Hiromitsu, M. Mikuriya, K. Kasuga, Chem. Papers 62, 410 (2008).

[15] D. Yoshioka, M. Handa, M. Mikuriya, I. Hiromitsu, K. Kasuga, Materials Science-Poland 23, 765 (2005).
[16] D. Yoshioka, M. Handa, M. Mikuriya, K. Kasuga, in: Advances in Coordination, Bioinorganic and Inorganic Chemistry, Eds. M. Melnik, J. Sima, M. Tatarko, Slovak Technical University Press, Bratislava 2005, p. 218.

[17] M. Mikuriya, K. Tanaka, M. Handa, I. Hiromitsu, D. Yoshioka, D. Luneau, Polyhedron 24, 2658 (2005).

[18] D. Yoshioka, M. Mikuriya, M. Handa, Chem. Lett 31, 1044 (2002).

[19] T.E. Vos, Y. Liao, W.W. Shum, J.-H. Her, P.W. Stephens, W.M. Reiff, J.S. Miller, J. Am. Chem. Soc. 126, 11630 (2004).

[20] T.E. Vos, J.S. Miller, Angew. Chem. Int. Ed. 44, 2416 (2005)

[21] J.S. Miller,Dalton Trans. 35, 2742 (2006).

[22] D. Matoga, M. Mikuriya, M. Handa, J. Szklarzewicz, Chem. Lett. 34, 1550 (2005).

[23] M. Mikuriya, D. Yoshioka, A. Borta, D. Luneau, D. Matoga, J. Szklarzewicz, M. Handa, New J. Chem. 35, 1226 (2011).

[24] M. Mikuriya, D. Yoshioka, R. Mitsuhashi, D. Luneau, D. Matoga, J. Szklarzewicz, M. Handa, Acta Phys. Pol. A 131, 120 (2017).

[25] M. Mikuriya, Y. Tanaka, D. Yoshioka, M. Handa, J. Supercond. Nov. Magn. 28, 1013 (2015).

[26] M. Mikuriya, Y. Tanaka, D. Yoshioka, M. Handa, Chem. J. Moldova 9, 93 (2014).

[27] M. Mikuriya, K. Ono, S. Kawauchi, D. Yoshioka, R. Mitsuhashi, M. Handa, Chem. J. Moldova 10, 48 (2015).

[28] M. Mikuriya, S. Kawauchi, K. Ono, R. Mitsuhashi, N. Yoshinari, T. Konno, H. Tanaka, M. Handa, J. Supercond. Nov. Magn. 30, 2007 (2017).

[29] J.-H. Her, P.W. Stephens, B.S. Kennon, C. Liu, J.S. Miller, Inorg. Chim. Acta 364, 172 (2010).

[30] O. Kahn, Molecular Magnetism, VCH publishers, New York 1993.

[31] K. Nakamoto, Infrared and Raman Spectra of Inorganic and Coordination Compounds, Part B: Application in Coordination, Oragnometallic, and Bioinorganic Chemistry, 6th ed. John Wiley \& Sons, New York 2009

[31] M. Mikuriya, S. Kawauchi, D. Yoshioka, R. Mitsuhashi, M. Handa, X-ray Struct. Anal. Online 34, 37 (2018). 